\title{
Construindo leitores: uma experiência de oficina de leitura'
}

\author{
Building readership: a reading \\ workshop experience
}

\author{
Sonia Saj PORCACCHIA ${ }^{2}$ \\ Leda Maria Codeço BARONE ${ }^{3}$
}

\begin{abstract}
Resumo
Este trabalho tem como objetivo estudar os efeitos da oficina de leitura sobre o "sujeito leitor": crianças com dificuldades de aprendizagem de leitura e escrita. Trata-se de um estudo de caso que utiliza o método clínico-qualitativo. Descreve-se uma oficina de leitura que tem como instrumento principal a leitura de história de literatura infantil, a partir da qual se abrem espaços para diferentes formas de participação das crianças, como diálogos, desenhos, narrativas, entre outras. Aproxima-se a oficina de leitura do espaço potencial postulado por Winnicott: as autoras consideram como campo clínico as sessões de leitura de histórias em que o contato com as crianças é realizado a partir do reconhecimento da importância do holding e da posição de sustentação da psicopedagoga. Os resultados demonstram que a oficina de leitura criou situações humanas nas quais foi possível refletir sobre as próprias condições de vida das crianças. Propiciaram-se também a construção de seus conhecimentos cognitivos e o interesse pelo significado das palavras, o que ressignificou e despertou o desejo de aprender a ler e a escrever.
\end{abstract}

Unitermos: Dificuldade de aprendizagem de leitura e escrita. Espaço potencial. Oficina de leitura.

\begin{abstract}
The project aims to study the effects of the Reading Workshop on the "target reader" who, in our case, are children with difficulties in learning to read and write. This is a case study using the clinical-qualitative method. It describes a Reading Workshop which uses, as its main tool, the reading of stories from children's literature from which space opens up for differentforms of participation by the children, such as dialogue, drawings, narratives amongst others. The Reading Workshop approximates to the Potential Space postulated by Winnicott in which the authors consider as a clinical field the story reading sessions where the contact with children is achieved by recognizing the importance of holding and the attitude of psycho-pedagogic support. The results show that the Reading Workshop created human situations in which it was possible to reflect upon the actual living conditions of children. It also allowed them to build their cognitive skills and an interest in the meaning of the words read, giving new meaning and stimulating the desire to learn to read and write.
\end{abstract}

Uniterms: Learning difficulty of reading and writing. Potential space. Workshop reading.

$\boldsymbol{\nabla \nabla \boldsymbol { \nabla } \nabla}$

1 Artigo elaborado a partir da dissertação de S.S. PORCACCHIA, intitulada "Oficina de leitura como intervenção psicopedagógica: literatura e espaço potencial". Centro Universitário Fundação Instituto de Ensino para Osasco, 2009.

2 Universidade de Santo Amaro, Pós-Graduação em Psicopedagogia Clínica Institucional. R. Isabel Schmidt, 349, Santo Amaro, 04743-030, São Paulo, SP, Brasil. Correspondência para/Correspondence to: S.S. PORCACCHIA. E-mail: <soniassp@gmail.com>.

3 Centro Universitário Fundação Instituto de Ensino para Osasco, Programa de Pós-Graduação Stricto Sensu em Psicologia Educacional. São Paulo, SP, Brasil. 
Não há como negar, na atualidade, a importância da leitura e da escrita. Quando essa aprendizagem não ocorre, a criança fica em uma posição de desvalia, o que lhe acarreta um pesado ônus que desperta seu sentimento de desvalorização no ambiente familiar, escolar e social mais amplo. O sujeito leitor, do ponto de vista desse trabalho, "é o sujeito inteiro, e o campo da leitura é o da subjetividade absoluta"; conforme esclarece Barthes (1988, p.51),"toda leitura procede de um sujeito e desse sujeito se separa apenas por mediações raras e tênues...".

A dificuldade nessa aprendizagem se deve a diferentes fatores - dentre eles aqueles relativos à pobreza extrema em que vive parte da população das periferias das grandes cidades -, e exige medidas que possam, se não os eliminar, pelo menos minimizá-los. Nesse sentido, é importante que os trabalhos de pesquisa acadêmica não se alienem dessa realidade, de modo que eles possam ser úteis à comunidade.

Este trabalho é oriundo de uma pesquisa acadêmica realizada em uma clínica-escola de psicopedagogia com um grupo de cinco crianças com dificuldade de aprendizagem de leitura e escrita. Trata-se de um estudo de caso que utiliza o método clínico-qualitativo e que tem como objetivo estudar os efeitos decorrentes da oficina de leitura sobre o "sujeito leitor", que, nesse caso, são crianças com dificuldade de aprendizagem de leitura e escrita.

Nomeou-se oficina de leitura uma atividade que tem como instrumento principal a leitura de histórias da literatura infantil, a partir da qual se abrem espaços para diferentes formas de participação das crianças, como diálogos, desenhos, narrativas, entre outras. É feita uma aproximação dessa oficina de leitura com o espaço potencial postulado por Winnicott. Nesse sentido, as autoras consideram como campo clínico as sessões de leitura de histórias em que é realizado o contato com as crianças, reconhecendo a importância do holding e a posição de sustentação da psicopedagoga.

\section{Literatura e construção do sujeito leitor}

Autores diferentes e provenientes de áreas diversas são enfáticos em demonstrar a importância da litera- tura na formação do sujeito. Tais autores afirmam que a literatura humaniza, que possibilita a construção e reconstrução do sujeito leitor, que facilita a elaboração de traumas vividos e a ressignificação da história pessoal.

Assim, escolheu-se utilizar como instrumento de trabalho a leitura de literatura infantil com base em autores que têm se ocupado em destacar a importância da leitura de literatura sobre o sujeito, seja a partir da observação de experiências de leitura, seja a partir da crítica literária.

Petit (2006), por exemplo, reconhece uma função reparadora da leitura de literatura e destaca que ler instaura um espaço de intersubjetividade entre leitor e texto; promove uma oportunidade para o sujeito falar em nome próprio tomando uma posição de sujeito; e, finalmente, desencadeia uma atividade narrativa interna.

Barone (1982; 2004a,b; 2005; 2006; 2007), ao estudar a relação entre leitor e texto literário, observa que a leitura de histórias tem uma dupla função: de transmissão de valores e sentidos de uma cultura, e terapêutica, na medida em que o leitor encontra no texto lido elementos seus ligados à sua própria indagação sobre a vida, seus conflitos, valores, desejos e crenças.

Safra (1984) incentiva os pais a contarem histórias com conteúdos relacionados aos conflitos de seus filhos como meio de estender o atendimento terapêutico. Gutfreind (2005), que utilizou a contação de histórias na psicoterapia de crianças com carência afetiva, observa a importância das narrativas curtas como antídoto contra o medo e como reforço de identidade das crianças. Caldin $(2001$; 2004; 2005) afirma que a literatura realmente tem uma função terapêutica.

A literatura é importante nas formas de educação familiar, grupal e escolar, e possui papel fundamental na formação da personalidade do ser humano como "força indiscriminadora e poderosa da própria realidade". Segundo Candido (1988, p.176), "ela não corrompe nem edifica, portanto; mas, trazendo livremente em si o que chamamos o bem e o mal, humaniza em sentido profundo, porque faz viver".

A escolha pela leitura de história em vez de simplesmente contar história se deu por se considerar o livro um importante objeto cultural e, por isso mesmo, necessário a todos e mais ainda àqueles cujas condições de vida Ihes negaram o acesso ao livro. Segundo Ro- 
bledo (Petit, 2006), um livro é, talvez, para aqueles que vivem em condições extremas de pobreza, a única saída para ultrapassar essa condição subumana.

\section{Literatura e espaço potencial}

O livro também pode ser visto como um objeto transicional na medida em que favorece o trânsito para a simbolização. Assim, apoiado em Winnicott, tomou-se a oficina de leitura como um espaço transicional/ potencial, entendido pelo autor como uma área intermediária de experimentação, ou seja, a terceira parte da vida do ser humano, para a qual contribuem tanto a realidade interna quanto a vida externa do indivíduo. A área intermediária, esclarece Winnicott (1975), é aquela concedida ao bebê entre a criatividade primária e a percepção objetiva da realidade. Sobre os fenômenos transicionais, diz o autor, eles representam os primeiros estágios da ilusão, precursores da possibilidade de simbolização.

A criatividade para Winnicott $(1975$, p.99) relaciona-se à forma como o indivíduo vive a realidade externa. No relacionamento de submissão à realidade externa, o mundo é reconhecido apenas como algo a que se deve ajustar ou adaptar-se. A submissão traz consigo um sentido de inutilidade e está associada à ideia de que nada importa e de que não vale a pena viver a vida. Viver criativamente constitui um estado saudável, e a submissão é uma base doentia para a vida.

Para Winnicott (1975), a possibilidade dos seres humanos viverem criativamente e sentirem que a vida vale a pena ser vivida está diretamente relacionada à qualidade e à quantidade de provisões ambientais no começo ou nas fases primitivas da experiência de vida de cada bebê. Algumas vezes, no decorrer do desenvolvimento da criança, surgem falhas no ambiente que a levam a permanecer paralisada em determinada fase de dependência - absoluta ou relativa -, impedindo-a de fortalecer seu sentimento de estar vivo, de sentir que a vida vale a pena ser vivida e de prosseguir em seu processo de aprendizagem.
A partir das colocações de Winnicott (1975) sobre o espaço potencial, com a possibilidade de estabelecimento de vínculo entre o viver criativo e o viver propriamente dito, considerou-se o espaço da oficina de leitura capaz de favorecer o sentimento que a criança tem de que a vida é real e significativa.

\section{A importância da posição de sustentação humana do terapeuta}

Como o trabalho foi desenvolvido com um grupo de crianças, é interessante rever como Winnicott (2005, p.213) concebe a noção de grupo: "a psicologia de grupo tem sua base na psicologia do indivíduo, e especialmente na integração pessoal deste" com "a continuidade do desenvolvimento emocional". Segundo esse autor, a criança parte da dependência em direção à independência, e, dessa maneira, o indivíduo sadio poderá ser"capaz de identificar-se com grupos cada vez mais amplos sem uma perda da noção de selfe de sua espontaneidade". Nesses casos, a base de formação grupal madura é a multiplicação de unidades individuais, a que Winnicott (2005) chama de superposição de unidades.

Winnicott (2005, p.219) reconhece ainda outro tipo de grupo, que ele define como "um conjunto de pessoas relativamente não integradas ${ }^{4 "}$, em diferentes graus. Nesses casos, conforme esclarece o autor, há a necessidade de se estabelecer uma "cobertura", no sentido de uma mãe que dá cobertura quando a criança necessita integrar seu self. Para Winnicott (2005), o trabalho de integração do self não provém dos indivíduos que fazem parte do grupo, mas da "cobertura"realizada pela terapeuta, e que na oficina foi feito pela psicopedagoga. O que Winnicott (2005) defende nesses casos é a importância da posição de sustentação humana que cabe ao terapeuta.

Quando realmente existe uma sustentação do terapeuta no grupo, estabelece-se uma"cobertura"; nesse estado, diz Winnicott (2005, p.219), os indivíduos que estão inseridos no grupo passam pelos três estágios

VरV

4 Para Winnicott (2005, p.216):"Antes da integração, o indivíduo é um conjunto não organizado de fenômenos sensório-motores contidos no ambiente externo. Depois da integração, o indivíduo É, ou seja, a criança humana atingiu o status de unidade, podendo já dizer EU SOU. O indivíduo possui agora uma membrana limitante, de forma que o que é não-eu é repudiado, é externo. Esse eu possui agora um dentro, onde podem reunir-se as memórias de experiências e edificar-se a estrutura infinitamente complexa que pertence ao ser humano". 
seguintes: a) Apreciam o fato de estarem sendo cobertos, e adquirem confiança; b) Começam a explorar a situação, tornando-se dependentes e regredindo à não integração; c) Começam, cada um por si mesmo, a adquirir alguma integração e, nesses momentos, valem-se da cobertura proporcionada pelo grupo, a qual lhes é necessária.

\section{Método}

O grupo era constituído por cinco crianças três meninos e duas meninas - de oito anos de idade, com dificuldade de aprendizagem da leitura e da escrita. Elas eram oriundas de contextos familiares com carências de toda ordem: afetiva, cultural e material. Seus pais, premidos por dificuldades diversas, mal conseguem subsistir, tendo pouca disponibilidade de tempo e de recursos pessoais para tratar dos filhos. Todo esse contexto fez com que os pais pouco usassem a linguagem narrativa com seus filhos, dificultando a todos a possibilidade de sonhar e pensar.

Com encontros semanais de duas horas durante um ano, a oficina de leitura foi o instrumento principal neste trabalho. Ela consistia inicialmente de leitura, realizada pela psicopedagoga, de textos de literatura infantil, que algumas vezes eram escolhidos por ela e outras pelo próprio grupo a partir da oferta de diferentes livros. A cada encontro havia um ritual de organização do espaço físico, que consistia em delimitá-lo com tapetes, onde todos podiam sentar e ouvir as histórias lidas, estabelecendo um espaço de segurança e confiança recíproca entre as crianças e a psicopedagoga. Após a leitura, as crianças eram convidadas a falar, desenhar, jogar ou realizar outra forma de expressão que pudesse ser tomada em consideração pela psicopedagoga.

O presente estudo foi aprovado pelo Comitê de Ética em Pesquisa do Centro Universitário - FIEO (CEP-UNIFIEO), projeto de pesquisa no 002/2007, e todos os participantes assinaram um termo de consentimento livre e esclarecido antes de sua inclusão na amostra.

\section{Resultados e Discussão}

Os dados consideraram o movimento do grupo ao longo da oficina de leitura e foram apresentados e discutidos qualitativamente a partir de três eixos:

\section{1) Interação das crianças dentro do grupo}

Nos primeiros encontros, cada uma fazia sua atividade individualmente, e mesmo se fosse solicitado algum tipo de auxílio, ninguém se colocava na situação de ajudar o outro. As crianças estavam muito voltadas para elas mesmas, havendo um total desinteresse e até mesmo desprezo por aquilo que o outro fazia.

Perceberam-se, muitas vezes, entre os meninos do grupo, situações de confronto, em que, por exemplo, sem motivo nenhum, um chutava o outro, levando a discussões e até mesmo a brigas físicas, quando a psicopedagoga precisava atuar de forma a separar as confusões e as brigas. Entretanto, as meninas eram mais tranquilas, mostrando-se mais amigas na interação com o grupo.

Aos poucos, percebeu-se a aproximação entre as crianças do grupo. Houve o caso de um dos meninos que, no início dos encontros, era muito agressivo, não participava das rodas, permanecendo sentado em uma cadeira com a cabeça baixa fingindo não estar ali. A psicopedagoga respeitava sua escolha apenas dizendo que quando ele quisesse seria bem-vindo a participar do grupo. Aos poucos ele começou a se interessar pelo que estava sendo lido e a aproximar-se devagar para olhar o livro e suas figuras, até que acabou sentando-se em um canto do tapete e fazendo parte da roda. Esse comportamento se repetiu por mais alguns encontros até que ele aceitou e encontrou um espaço de segurança e confiança, muitas vezes chegando a se deitar no ombro da psicopedagoga, parecendo que, naquele momento, já podia confiar em alguém e se aconchegar. Então, mais tranquilo, passou a ser o primeiro a pegar os tapetes, os livros e a organizar a roda de leitura, e a se colocar para realizar a leitura da história.

Também nas primeiras sessões, após a leitura da história, ninguém falava nada livremente. A psicopedagoga tinha que perguntar o que acharam da história lida, e alguns respondiam "legal". Passados alguns encontros, um participante começou a falar sobre as associações surgidas a partir da leitura; posteriormente, todos se sentiam à vontade para falar, quando então passaram a falar compulsivamente e, ao mesmo tempo, a disputar um espaço para ver quem falava primeiro, e quem podia falar mais tempo.

Assim, após alguns encontros, observou-se que a leitura de histórias estabelecia ligações entre o acon- 
tecimento de uma história lida e a narrativa das próprias histórias de vida da criança, possibilitando, dessa maneira, um processo de autoconstrução e de elaboração de sentido, conforme observa Petit (2006).

A disputa entre as crianças foi se modificando lentamente: elas passaram a respeitar a vez do outro, falavam pausadamente e principalmente abriram um espaço para ouvir o que o outro falava e, muitas vezes, usavam, com o colega, palavras de consolo quando surgia alguma situação muito forte de dor ou de sofrimento. Observou-se, na interação do grupo, uma posição de solidariedade e de ajuda mútua.

Assim, a oficina de leitura propiciou às crianças uma vida e um mundo reconhecidos como próprios, fazendo com que elas fossem capazes de se responsabilizar por suas ações ou omissões, e de assumir os aplausos pelo sucesso ou as censuras pelas falhas.

Dessa maneira, a oficina de leitura se colocou como uma área segura de experimentação - para qual contribuíram tanto a realidade interna quanto a externa -, em que a psicopedagoga teve a capacidade de conter os conflitos da criança e propiciar uma relação de confiança que permitiu a resolução dos conflitos da própria criança.

A interação observada no grupo faz pensar no que Winnicott (2005) diz sobre o grupo organizado e a sustentação do terapeuta, uma vez que a oficina de leitura e o manejo da psicopedagoga possibilitaram um espaço de segurança e confiança nos encontros. Dentro da oficina de leitura, tomada como Espaço Potencial, as crianças puderam regredir a um estado de dependência e não integração porque existiu a sustentação/cobertura da psicopedagoga. Lentamente, cada um, por si mesmo, foi encontrando sua integração.

Pode-se afirmar que a oficina de leitura propiciou diversos encontros de acolhimento e diferentes trocas subjetivas, criando assim uma narrativa interna em cada criança, e permitindo um espaço de autonomia e a possibilidade para a constituição de sujeito, como ressalta Petit (2006).

\section{2) Interação com a psicopedagoga}

No início, a relação com a psicopedagoga era de desconfiança e insegurança, como por exemplo, quando o menino citado acima não queria interagir e se isolava assustado no canto da sala. Da mesma forma, algumas vezes, terminada a leitura da história, as meninas, especialmente, pediam para ir ao banheiro ou para beber água, possivelmente por estarem com medo de se colocarem e por não quererem falar sobre o que pensavam sobre a história lida. A psicopedagoga tinha consciência da necessidade de deixar aflorar um sentimento de confiança nas crianças, oferecendo um ambiente acolhedor e propício ao surgimento da segurança, semelhante ao espaço potencial proposto por Winnicott (1975). Para esse autor, possibilitar um ambiente responsivo e empático significa criar um vínculo para a construção de confiança e para que a criança tenha o tempo necessário para a eclosão de sua criatividade.

Na oficina de leitura, as crianças realmente observavam os gestos da psicopedagoga, o tom da voz, suas expressões faciais, gestos de alegria, de tristeza, de amor, de raiva e de compaixão trazidos nas histórias lidas. Ao mesmo tempo, a voz acolhia e ancorava qualquer sentimento de medo ou angústia que surgisse, fortalecendo o sentimento de si mesmo, favorecendo a expansão narcísica e possibilitando novos espaços para a identificação. Para Morais (1996), a leitura em voz alta desperta na criança a vontade de ler por si mesma; ela mostra esse desejo quando, ao se deitar para dormir, após a leitura de história, imita os pais, também desejando ler, buscando encontrar a magia das palavras lidas. Nesse sentido, percebe-se a referência à importância do outro na vida da criança, o que nos faz pensar na observação de Winnicott sobre a influência da família e do ambiente como facilitadores do desenvolvimento emocional da criança.

No decorrer da oficina, ofereceu-se a leitura de histórias com função lúdica e criativa capaz de despertar o prazer pela leitura e a imaginação, de maneira que pudesse suprir as falhas do ambiente em investir no desejo de ler, conforme salienta Barone (2005). Aos poucos, as crianças do grupo conseguiram falar o que pensavam sobre a história lida, buscando narrar suas vivências e os sentimentos que surgiram naquele momento, e demonstravam prazer em ouvir e contar histórias.

Devagar as crianças desenvolveram a confiança e a tranquilidade, aceitando estar no grupo com a psicopedagoga. Com as experiências vividas a cada sessão, elas se permitiram regredir quando sentiam necessidade. 
Via-se essa situação quando a partir das atividades propostas as crianças se recusavam a realizar uma tarefa, deixando claro que não conseguiam fazer, e não faziam, se não tivesse a ajuda da psicopedagoga. Esse fato mostrava o momento do retorno à não integração, em que ela precisava temporariamente se ligar novamente à terapeuta para poder realizar a sua atividade, mostrando a necessidade do holding vivo do ser humano, para que houvesse nova oportunidade para reintegração do self, conforme Winnicott (2005) concebeu na noção de grupo. Com a "cobertura"/sustentação suficientemente boa da psicopedagoga, as crianças puderam descobrir seu próprio self, podendo existir e sentir-se real.

Assim, se a oficina de leitura favorecia o surgimento de angústias e de sofrimentos provocados pelas histórias ouvidas, ao mesmo tempo oferecia oportunidade às crianças de encontrar um destino diferente para esses sentimentos através da possibilidade de narrar e da sustentação oferecida pela psicopedagoga. Parece também que a experiência provocou certa consideração pela dor do outro, uma vez que as crianças passaram a ouvir e a acolher o relato dos colegas.

\section{3) A disponibilidade do grupo para realização das tarefas propostas}

No início havia um desinteresse das crianças por aquilo que era proposto para o grupo. Desde as primeiras sessões observou-se que as crianças não demonstravam interesse pelos livros e pela leitura das histórias. Quando se oferecia o livro para leitura, todas se negavam a ler, e pareciam até ter medo de pegá-lo. Algumas chegaram às seguintes verbalizações: "Ler como a professora faz nas aulas, que coisa chata!"; ou "Eu não quero nem pensar em ler".

Gillig (1999) fala da existência de um desinteresse da criança em relação àquilo que se relaciona ao escolar, e, no caso das crianças desse grupo, pode-se supor que a leitura, para elas, colocava-se nesse lugar. Parecia que existia uma barreira entre o seu mundo (afetivo e social) e o espaço escolar (um símbolo da cultura).

Pode-se contar, como exemplo, a dificuldade apresentada por uma das meninas, que necessitava, o tempo todo, de autorização e aprovação para aquilo que se propunha a fazer. Tinha-se a impressão de que ela não se autorizava a pensar, precisando o tempo todo de alguém que pensasse e fizesse as atividades por ela, que a impulsionasse, dizendo-lhe a direção a seguir, parecendo sempre estar perdida nas atividades solicitadas. Com o passar dos encontros, a história despertou seus sentimentos, e, aos poucos, ela se permitiu refletir, pensar e falar de si mesma.

Como ressaltou Petit (2006), em situações de crise, deve haver o estabelecimento de um espaço transicional, para que a criança reencontre a capacidade de restabelecer os laços seja com o mundo interno, seja com o externo, e, assim, recupere a capacidade de brincar, simbolizar, aprender, pensar, criar.

Assim, a oficina de leitura sobreposta pelo espaço potencial tem a mesma potencialidade deste, uma vez que propicia uma área em que a criança pode criar o mundo em que vive ao mesmo tempo em que se adapta ao mundo objetivamente dado. A oficina de leitura se coloca, também, como um espaço facilitador, quando permite um encontro das crianças com elas mesmas, na inter-relação da realidade subjetiva e a objetivamente percebida.

Nesse sentido, o livro foi utilizado como um suposto objeto transicional, lembrando que, para Winnicott (1975), o uso do objeto transicional favorece o trânsito para a simbolização e a aceitação da realidade. Portanto, o uso de objetos pessoais ou compartilhados pode auxiliar o amadurecimento emocional do indivíduo, propiciando a diferenciação do que é parte do seu psiquismo interno, do que é a parte compartilhada e do que é parte do mundo externo compartilhado com a cultura.

No caso dessa oficina de leitura, pode-se afirmar que o livro somado à história lida propiciou um novo "brilho no olhar" das crianças. Através dos livros e suas histórias, as crianças puderam apropriar-se de suas experiências pessoais, algumas dolorosas, passando a narrá-las.

Pode-se pensar que a partir da repetição de vários encontros, a leitura passou a fazer parte da vida das crianças como algo prazeroso. Observa-se que a história serviu como um objeto transicional que permitiu a passagem do mundo da onipotência imaginária à experiência cultural. Assim, nessas situações, outras experiências culturais podem ser sobrepostas; entre elas pode-se pensar, nesse caso, na aprendizagem da leitura e da 
escrita, obtendo-se a suposta "cura", tão necessária para essas crianças.

Passados alguns encontros, percebeu-se uma mudança no comportamento dessas crianças, que passaram a prestar atenção ao que estava sendo lido, interessando-se por seu conteúdo, pelas figuras, desenhos, e até mesmo pela aprendizagem e significado das palavras lidas. Como diz Penac (1993, p.46), com a leitura de histórias para a criança, o que ela aprende "primeiro não é o ato, mas o gesto do ato, e que, se por um lado, ela [a leitura] pode ajudar na aprendizagem, essa ostentação é, acima de tudo, destinada a tranquilizá-la".

A menina citada acima, em especial, conseguiu uma melhor organização de seus pensamentos. Hoje sua fala é clara e objetiva. Em uma sessão, ela falou com muito orgulho que, na sua casa, era ela quem lia as histórias para seus pais e fazia as atividades escolares com sua irmãzinha. O que aprendeu a fazer na oficina de leitura deu-Ihe novos significados e sentidos nas suas vivências familiares. Agora ela se sentia importante, de posse de um saber, uma vez que podia levar para sua casa o que aprendeu a fazer na oficina de leitura.

A oficina, através da leitura de histórias seguidas de diferentes atividades, permitiu que as crianças do grupo se abrissem para a fantasia, para o mundo imaginário, possibilitando assim o movimento do pensamento, a simbolização e a construção de sentido. Pode-se afirmar que a leitura as ajudou a se construir e a se descobrir autora de sua vida, sujeito de seu destino, mantendo a humanidade, o sentido da vida.

\section{Considerações Finais}

O espaço oferecido pela oficina de leitura favoreceu a criatividade e sustentou várias experiências humanas necessárias ao desenvolvimento do self, porque ele se constituiu como espaço de acolhimento e confiança (holding) sustentado pela psicopedagoga, e porque foi mediado por um produto cultural - o livro altamente valorizado, e, por último, porque o texto literário facilitou o processo de humanização. Assim, a oficina de leitura permitiu a percepção criativa, isto é, a experiência da ilusão, auxiliando a criança a construir a subjetividade na percepção objetiva da realidade e a partir daí a possibilidade de simbolização.
Considera-se, assim, legítimo aproximar a experiência da oficina de leitura ao espaço potencial de Winnicott, uma vez que ler histórias para crianças possibilitou o "viver criativo" e o "estar vivo", conforme ele propõe.

A leitura de histórias para essas crianças passou a ter dois significados diferentes e essenciais na reconstrução de suas aprendizagens: primeiro porque a leitura de histórias participou, como facilitadora e mediadora, da ressignificação de suas próprias histórias de vida. 0 texto literário criou situações humanas que puderam refletir as próprias condições de vida das crianças. Como segundo significado, a história participou da construção de seus conhecimentos cognitivos, uma vez que as crianças passaram a se interessar pelo significado de algumas palavras que não tinham conhecimento. E, devagar, cada criança, a seu tempo, teve despertado seu desejo de ler e escrever.

\section{Referências}

Barone, L. M. C. (1982). Literatura infantil e ansiedade: um estudo de reações ao texto. Dissertação de mestrado não-publicada, Instituto de Psicologia, Universidade de São Paulo.

Barone, L. M. C. (2004a). Brincar e narrar: possibilidades de organização da experiência. Revista de Psicopedagogia, 21 (66): 239-244.

Barone, L. M. C. (2004b). Narrativa e cura: a função terapêutica da palavra. In F. Herrmann \& T. Lowenkron (Orgs.), Pesquisando com o método psicanalítico (pp.277-285). São Paulo: Casa do Psicólogo.

Barone, L. M. C. (2005). De ler o desejo ao desejo de ler: uma leitura do olhar do psicopedagogo. Petrópolis: Vozes.

Barone, L. M. C. (2006). Em defesa da leitura. In M. S. Andrade \& M. L. P. B. Franco (Orgs.), Aprendizagem humana (pp.87-99). São Paulo: Casa do Psicólogo.

Barone, L. M. C. (2007). Apontamentos para construção do sujeito leitor. Construção Psicopedagógica, 15 (12), 27-37.

Barthes, R. (1988). O rumor da língua. São Paulo: Brasiliense.

Caldin, C. F. (2001). A leitura como função terapêutica: biblioterapia. Encontros Bibli: Revista Eletrônica de Biblioteconomia e Ciência da Informação, 6 (12). Recuperado em março 2, 2009, disponível em <http://www.encontrosbibli.ufsc.br>.

Caldin, C. F. (2004). A aplicabilidade terapêutica de textos literários para crianças. Encontros Bibli: Revista Eletrônica de Biblioteconomia e Ciência da Informação, 18, 72-89. Recuperado em março 2, 2009, disponível em <http:// redalyc.uaemex.mx/pdf/147/14701806.pdf>. 
Caldin, C. F. (2005). Biblioterapia para a classe matutina de aceleração da escola de educação básica Dom Jaime de Barros Câmara: relato de experiência. Recuperado em março 2, 2008, disponível em: <http://www.acbsc.org. br/ revista/ojs/viewarticle.php?id=100>.

Candido, A. (1998). Vários escritos (4a ed.). São Paulo: Duas Cidades.

Gillig, J. M. (1999). O conto na psicopedagogia. Porto Alegre: Artes Médicas Sul.

Gutfreind, C. (2005). O terapeuta e o lobo: a utilização do conto na psicoterapia da criança (2a ed.). São Paulo: Casa do Psicólogo.

Morais, J. (1996). A arte de ler. São Paulo: Unesp.

Pennac, D. (1993). Como um romance. Rio de Janeiro: Rocco.
Petit, M. (2006). A leitura em espaços de crise. Revista Brasileira de Psicanálise, 40 (3), 149-167.

Safra, G. (1984). Um Método de consulta terapêutica através do uso de estórias infantis. Dissertação de mestrado não-publicada, Instituto de Psicologia, Universidade de São Paulo.

Winnicott, D. W. (1975). O brincar e a realidade. Rio de Janeiro: Imago.

Winnicott, D. W. (2005). A família e o desenvolvimento individual (3a ed.). São Paulo: Martins Fontes.

Recebido em: 9/10/2009

Versão final reapresentada em: 15/7/2010

Aprovado em: 11/3/2011

402 